\title{
Use, Attitudes and Knowledge of Complementary and Alternative Drugs (CADs) Among Pregnant Women: a Preliminary Survey in Tuscany
}

\author{
Francesco Lapi ${ }^{1,2}$, Alfredo Vannacci ${ }^{1,2}$, Martina Moschini $^{1,2}$, Fabrizio Cipollini ${ }^{3}$, \\ Maria Morsuillo ${ }^{1,2}$, Eugenia Gallo ${ }^{1,2}$, Grazia Banchelli, ${ }^{1,2}$, Enrica Cecchi ${ }^{1,2,4}$, \\ Marina Di Pirro ${ }^{1,2}$, Maria Grazia Giovannini ${ }^{2}$, Maria Teresa Cariglia ${ }^{2}$, Luigi Gori ${ }^{5}$, \\ Fabio Firenzuoli ${ }^{5}$ and Alessandro Mugelli,
}

${ }^{1}$ Tuscan Regional Centre of Pharmacovigilance, ${ }^{2}$ Department of Preclinical and Clinical Pharmacology, Florence, ${ }^{3}$ Department of Statistical Science, University of Florence, ${ }^{4}$ Department of Emergency Medicine, ASL 4 Hospital, Prato and ${ }^{5}$ Centre of Natural Medicine, ASL 11 Hospital, Empoli, Italy

To explore pregnant women's use, attitudes, knowledge and beliefs of complementary and alternative drugs (CADs) defined as products manufactured from herbs or with a natural origin. A preliminary survey was conducted among 172 pregnant women in their third trimester of pregnancy, consecutively recruited in two obstetrical settings; 15 women were randomly selected to compute a test-to-retest analysis. Response rate was $87.2 \%$. Test-to-retest analysis showed a questionnaire's reproducibility exceeding a $K$-value of 0.7 for all items. Mean age was $32.4 \pm 0.4$ years; most women were nulliparae $(62.7 \%)$. The majority of subjects $(68 \%)$ declared to have used one or more CADs during their lifetime; $48 \%$ of pregnant women reported taking at least one CAD previously and during the current pregnancy. Women's habitual use of CADs meant they were at higher risk of taking CADs also during pregnancy (adjusted odds ratio $=10.8 ; 95 \%$ confidence interval: $4.7-25.0$ ). Moreover, $59.1 \%$ of the subjects were unable to correctly identify the type of CADs they were using. The majority of women resorted to gynecologists as the primary information source for CADs during pregnancy, while they mainly referred to herbalists when not pregnant. Habitual use of CADs seems to be a strong predictor for their ingestion also during pregnancy; in addition most subjects were unable to correctly identify the products they were taking. In the light of the scanty data concerning the safety of CADs during pregnancy, these preliminary results confirm the need to investigate thoroughly the situation of pregnant women and CADs consumption.

Keywords: CAM - herbal products - natural origin - pregnancy

\section{Introduction}

According to the definition provided by the National Center for Complementary and Alternative Medicine

For reprints and all correspondence: Francesco Lapi, Tuscan Regional Centre of Pharmacovigilance, Department of Pharmacology, University of Florence, Viale G. Pieraccini ${ }^{\circ} 650139$, Florence, Italy.

Tel: + 390554271255; Fax: + 390554271255;

E-mail: francesco.lapi@unifi.it
(NCCAM), 'Complementary and Alternative Medicine $(\mathrm{CAM})$ is a broad domain of healing resources that encompasses all health systems, modalities and practices and their accompanying theories and beliefs, other than those intrinsic to the politically dominant health system of a particular society or culture in a given historical period. CAM includes all such practices and ideas selfdefined by their users as preventing or treating illness or promoting health and well-being' (1). 
In 1996, the British Medical Journal, published the news 'Complementary medicine is booming worldwide' $(2,3)$. Consistently in the last decade, an important increase in the use of CAM has been observed in Europe, USA and Australia $(2,4,5)$, in which most studies showed women as the major users of alternative medicines when compared with men $(2,4,5)$. In Italy, during the period 1997-99, almost 9 million people used at least one non-conventional therapy, where homeopathy was the most commonly used ( $8.2 \%$ of the population). The main reason for use was concern about the toxicity of conventional medicines (6).

Similarly, the attitude of pregnant women towards CAM, particularly with regard to complementary and alternative drugs (CADs), including homeopathy, herbal drugs and other products of natural origin, seems to be an appealing approach to guarantee the well-being of their unborn children. Nevertheless, CADs are not always subject to the same regulations as conventional medicines and there is often little concerning purity, safety or teratogenicity of this kind of medications. These aspects were discussed in 1996 by a Canadian pregnancy information centre, the Mother-Risk Centre (7) as well as by the most recent medical literature (8-14). Some remedies such as Valerian (Valeriana officinalis), Bearberry (Arctostaphylos uva-ursi) and Gingko (Gingko biloba) can be contraindicated in pregnancy in the light of little or absent data on their safety profile (8-14). In fact, only few studies have investigated the effect of herbal drugs on human pregnancy outcome $(15,16)$.

In Italy specific surveys that investigate the attitude of pregnant woman towards CADs are still lacking. The only available information on this issue, focused on herbal medications, has been reported in a survey performed by Zaffani et al. (17): $35.23 \%$ of the sample admitted to use herbal drugs during pregnancy or to treat their children's diseases.

Additionally, because of the well-known CADs heterogeneity, patients might have difficulty in recognizing or identifying the product they are using. This issue is widely debated both in Italy and in other western countries but, to our knowledge, an epidemiological evaluation of this topic is still absent.

Thus, the purpose of this preliminary study was to explore the attitudes, beliefs, knowledge of CADs in a sample of pregnant Italian women.

\section{Methods}

\section{Study Population}

This preliminary survey was conducted over a 2-month period (twice a week, from June 1 to July 31, 2006) in two gynecology wards of two general hospitals located in Florence (Tuscany, Italy), after institutional authorization was received. The sample population consisted of women in the last trimester of pregnancy, not randomly selected, attending the outpatient department or admitted as inpatients to delivery.

All potential participants, consecutively recruited, received written and oral information about the study and written informed consent was obtained.

\section{Data Collection}

Data were collected by means of a semi-structured (Appendix 1) questionnaire administered by a trained midwife using a face-to-face interview of $\sim 20 \mathrm{~min}$. Before each interview women received a definition of CADs, generally defined as any type of product manufactured from plants or with natural origin.

The questionnaire was composed of 20 items, close and open-ended questions, divided into three sections. The first section comprised the patient's demographic data, the eventual presence of chronic diseases and use of CADs outside or in previous pregnancies. The second section investigated the use of CADs during the current pregnancy and the timing of administration (I, II, III trimester). The trained interviewer was instructed to get as much information as possible on CADs ingested by pregnant women. Women in the study were also asked to classify products in the following categories: homeopathic drugs, Bach flowers, herbal drugs, herbal preparations and natural products. Afterwards each product was correctly classified by a trained specialist by means of the European Pharmacopeia (18).

Finally, the third and last section investigated information sources on CADs: women were asked, through close-ended questions, what was their usual source of information about CADs (the choices were: pharmacist, herbalist, midwife, general practitioner, internet, friends/ family, magazines); two close-ended questions finally investigated the beliefs of pregnant women about the safety and efficacy of CADs.

The questionnaire was designed and planned according to the most recent methodological literature (19-23). It was validated by an ad hoc panel of experts (pharmacologists, epidemiologists, toxicologists, pharmacists and clinicians) of the Tuscan Regional Centre of Pharmacovigilance, a clinician of the regional referring Centre of Natural Medicine and a group of gynecologists and midwives of both hospital settings. At first a focus group of six volunteers, as a small target population, participated in a systematic discussion, concerning questionnaire structure, guided by a moderator. In this way we evaluated the comprehension level of all questions.

Furthermore, besides the experts' review, the questionnaire's validity was controlled using a 'lie-catching' item. After collection of demographic data the question, 'Have you ever used CADs in your life? (yes/no)' was useful for ascertaining whether the patient had ever used CADs 
in general. The answer to this item had to report the same construct of at least one of the two subsequent questions, 'Have you ever used CADs during the current pregnancy? (yes/no)' or 'Have you ever used CADs in a previous pregnancy or outside of pregnancy? (yes/no)'. A positive answer, obtained at least once for these two items, was coded as a dichotomous variable: the combinations of answers 'yes/yes', 'yes/no', 'no/yes' were coded with the same value which was different from 'no/ no'; so this new variable could be compared, by means of a $2 \times 2$ table with the response of the 'lie-catching' item.

Finally, to evaluate data reliability, 15 women, identified by means of an anonymous alphanumeric code, were randomly selected for a test-to-retest investigation. The questionnaire was administered twice, with an interval of 2 weeks between each interview. Closed-ended items with more than one possible answer were not considered for evaluation of agreement level.

\section{Data Analysis}

Categorical variables were expressed as percentage value and analyzed with the Chi-square $\left(\chi^{2}\right)$ test, while continuous variables were reported as mean value \pm Standard Error of Mean (SEM) and analyzed using the $t$-test or ANOVA. To check validity and reliability of the questionnaire, evaluated by means of lie-catching and test-to-retest, respectively, a $K$ of Cohen was computed: $K$-value, according to Landis and Koch was categorized as fair (0.2-0.4), moderate (0.4-0.6), good (0.6-0.8) and very good $(0.8-1)$. Finally, to identify possible predictors of CADs use, a multivariate logistic model was computed. Variables included in the model were age, parity, as well as participants' characteristics that were possibly found to be statistically different between the 'user' and 'non-user' groups.

A $P$-value $<0.05$ was considered statistically significant. All analyses were performed using SPSS for Windows, version 14.0 (Chicago Inc., Illinois, USA).

\section{Results}

\section{Participants}

A total of 172 women were consecutively contacted, with a response rate of $87.2 \%$. The mean age of the final sample (150 women) was $32.4 \pm 0.4$ years; most women were nulliparae $(62.7 \%)$ while $30,5.3$ and $2 \%$ were primiparae, secondiparae and pluriparae, respectively. With regard to their educational level, $72 \%$ of women had a university degree. Nineteen (12.6\%) participants reported a chronic disease: diabetes (6 cases), asthma (9 cases), hepatitis ( 2 cases) and blood coagulation disorders (2 cases); 10 subjects reported concurrent use of drugs: acetaminophen ( 2 cases), fraxiparine ( 2 cases), aspirin (1 case), levotiroxine (3 cases) and corticosteroids ( 2 cases).

The majority of subjects $(68 \%)$ declared to have used at least one CAD during their life while $48 \%$ reported taking at least one of these products during current pregnancy.

\section{Questionnaire's Validity and Reliability}

Evaluation of validity revealed a very good agreement $(K=0.9 ; P<0.001)$ between dummy variable and the lie catcher item 'Have you ever used CADs in your life? (yes/no)'. In fact only two women showed disagreeing answers.

Consistently all $K$-values, computed by means of testto-retest evaluation, showed the questionnaire's reproducibility exceeding 0.7 for every item.

Specifically the two key questions, 'Have you used CADs in a previous pregnancy or outside of pregnancy? (yes/no)' and 'Have you ever used CADs during the current pregnancy? (yes/no)', reported a $K$ of 0.9 $(P<0.001)$ for both dichotomic answers.

\section{Use of CADs Outside and/or in a Previous Pregnancy}

The majority of women were nulliparae. In fact, only 10 women reported to have taken CADs during previous pregnancies. For this reason, the analysis regarding previous use of CADs was mainly based on pregnancyfree periods. The characteristics of women, divided into 'users' or 'non-users' of CADs are reported in Table 1.

Table 1. Population characteristics of 150 Italian women according to lifetime use $(n=102)$ or non-use $(n=48)$ of CADs

\begin{tabular}{|c|c|c|c|c|c|}
\hline \multirow[b]{2}{*}{ Variables } & \multicolumn{2}{|c|}{ 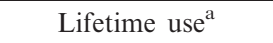 } & \multirow[b]{2}{*}{$P$} & \multirow[b]{2}{*}{$t$} & \multirow[b]{2}{*}{$\chi^{2}$} \\
\hline & Users & Non-users & & & \\
\hline Age & $32.4 \pm 1.0$ & $32.5 \pm 0.8$ & 0.901 (NS) & 0.125 & - \\
\hline Weeks of amenorrhea & $36.3 \pm 0.7$ & $35.9 \pm 1.0$ & $0.740(\mathrm{NS})$ & 0.333 & - \\
\hline \multicolumn{6}{|l|}{ Chronic disease ${ }^{\mathrm{b}}$} \\
\hline Yes & $14(13.7)$ & $5(10.4)$ & - & - & - \\
\hline No & $88(86.3)$ & $43(89.6)$ & $0.570(\mathrm{NS})$ & - & 0.323 \\
\hline \multicolumn{6}{|l|}{ Level of education } \\
\hline $\begin{array}{l}\text { Secondary or high } \\
\text { school }\end{array}$ & $17(23.6)$ & $25(32.1)$ & - & - & - \\
\hline University degree & $55(76.4)$ & $53(67.9)$ & $0.250(\mathrm{NS})$ & & 1.323 \\
\hline \multicolumn{6}{|l|}{ Parity } \\
\hline Nulliparae & $68(66.7)$ & $26(54.2)$ & - & - & - \\
\hline $\begin{array}{l}\geq 1 \text { previous } \\
\text { pregnancies }\end{array}$ & $34(33.3)$ & $22(45.8)$ & 0.140 (NS) & - & 2.180 \\
\hline
\end{tabular}

Continuous variables (items) are expressed as mean value \pm SEM; categorical variables as absolute numbers and percentage values: $n(\%)$. NS: not significant.

${ }^{a}$ Refers to the lie-catching item 'Have you ever used CADs? (yes/no)'. ${ }^{\mathrm{b}}$ Diabetes, asthma, hepatitis and blood coagulation disorders. 
$\chi^{2}$ - and $t$-test did not show any difference among all variables.

\section{Use of CADs during the Current Pregnancy}

The characteristics of participants, according to CADs use during the current pregnancy, are presented in Table 2. Previous use of CADs and concurrent use of conventional drugs was significantly different between the two groups. Women who were used to taking CADs, in previous or out of pregnancy, reported a significantly higher prevalence $(84.7 \%$ versus $37.2 \% ; P<0.001)$ of CAD use also during the current pregnancy. Analogous findings were present for women who were taking a concurrent pharmacological therapy $(13.9 \%$ versus $0 \%$; $P=0.001)$. A logistic regression model including age, previous CADs use, parity, confirmed these results: women with previous CAD use showed a 10.8-fold increased risk of taking CADs also during the current pregnancy [adjusted Odds Ratio $(\mathrm{OR})=10.8 ; 95 \%$ confidence interval (CI): 4.7-25.0]. The other characteristics included in the model did not significantly differ between women using and not using CADs; the most commonly used CADs are reported in Table 3. The variable 'concurrent pharmacological therapy' was not included in the model because one cell reported a null value. Moreover, no significant difference was revealed among numbers of CADs probably taken in different periods of pregnancy (Table 4).

The percentage of women, who were not aware of the type of CADs they were using, increased with the number of products taken. Only $15.2 \%$ of subjects were able to correctly classify all CADs that they were taking, while
Table 2. Population characteristics of 150 Italian women according to use $(n=72)$ or non-use $(n=78)$ of CADs during current pregnancy

\begin{tabular}{|c|c|c|c|c|c|}
\hline \multirow[b]{2}{*}{ Variables } & \multicolumn{2}{|c|}{ Current pregnancy } & \multirow[b]{2}{*}{$P$} & \multirow[b]{2}{*}{$t$} & \multirow[b]{2}{*}{$\chi^{2}$} \\
\hline & Users & Non-users & & & \\
\hline Age & $31.9 \pm 0.6$ & $33.0 \pm 0.5$ & $0.177(\mathrm{NS})$ & 1.357 & - \\
\hline $\begin{array}{l}\text { Weeks of } \\
\text { amenorrhea }\end{array}$ & $35.7 \pm 0.8$ & $36.6 \pm 0.7$ & $0.435(\mathrm{NS})$ & 0.783 & - \\
\hline \multicolumn{6}{|c|}{ Presence of chronic disease ${ }^{\mathrm{a}}$} \\
\hline Yes & $9(12.5)$ & $10(12.8)$ & - & - & - \\
\hline No & $63(87.5)$ & $68(87.2)$ & $0.953(\mathrm{NS})$ & & 0.003 \\
\hline \multicolumn{6}{|c|}{ Concurrent use of drugs ${ }^{\mathrm{b}}$} \\
\hline Yes & $10(13.9)$ & 0 & - & - & - \\
\hline No & $62(86.1)$ & $78(100)$ & 0.001 & - & 11.067 \\
\hline \multicolumn{6}{|c|}{ Level of education } \\
\hline $\begin{array}{l}\text { Secondary or } \\
\text { high school }\end{array}$ & $17(23.6)$ & $25(32.1)$ & - & - & - \\
\hline Degree & $55(76.4)$ & $53(67.9)$ & 0.250 (NS) & - & 1.323 \\
\hline \multicolumn{6}{|c|}{ Previous use of $\mathrm{CADs}^{\mathrm{c}}$} \\
\hline Yes & $61(84.7)$ & $29(37.2)$ & - & - & - \\
\hline No & $11(15.3)$ & $49(62.8)$ & $<0.001$ & - & 35.261 \\
\hline \multicolumn{6}{|l|}{ Parity } \\
\hline Nullipara & $44(61.1)$ & $50(64.1)$ & - & - & - \\
\hline $\begin{array}{l}\geq 1 \text { previous } \\
\text { pregnancies }\end{array}$ & $28(38.9)$ & $28(35.9)$ & $0.705(\mathrm{NS})$ & - & 0.143 \\
\hline
\end{tabular}

Continuous variables (items) are expressed as mean value $\pm \mathrm{SEM}$; categorical variables as absolute numbers and percentage values: $n(\%)$. A $p<0.05$ value was considered statistically significant; NS: not significant.

${ }^{\mathrm{a} D}$ Diabetes, asthma, hepatitis and blood coagulation disorders.

${ }^{\mathrm{b}}$ Acetaminophen (2 cases), fraxiparine (2 cases), aspirin (1 case), levothyroxine (3 cases), corticosteroids (2 cases).

${ }^{\mathrm{c}}$ Referred to items 'Have you used CADs in a previous pregnancy or outside of pregnancy? (yes/no)'; previous use of CADs, during previous pregnancies $(n=10)$ or outside pregnancies $(n=80)$.

Table 3. Prevalence of CADs use and reasons for use according to interview with women

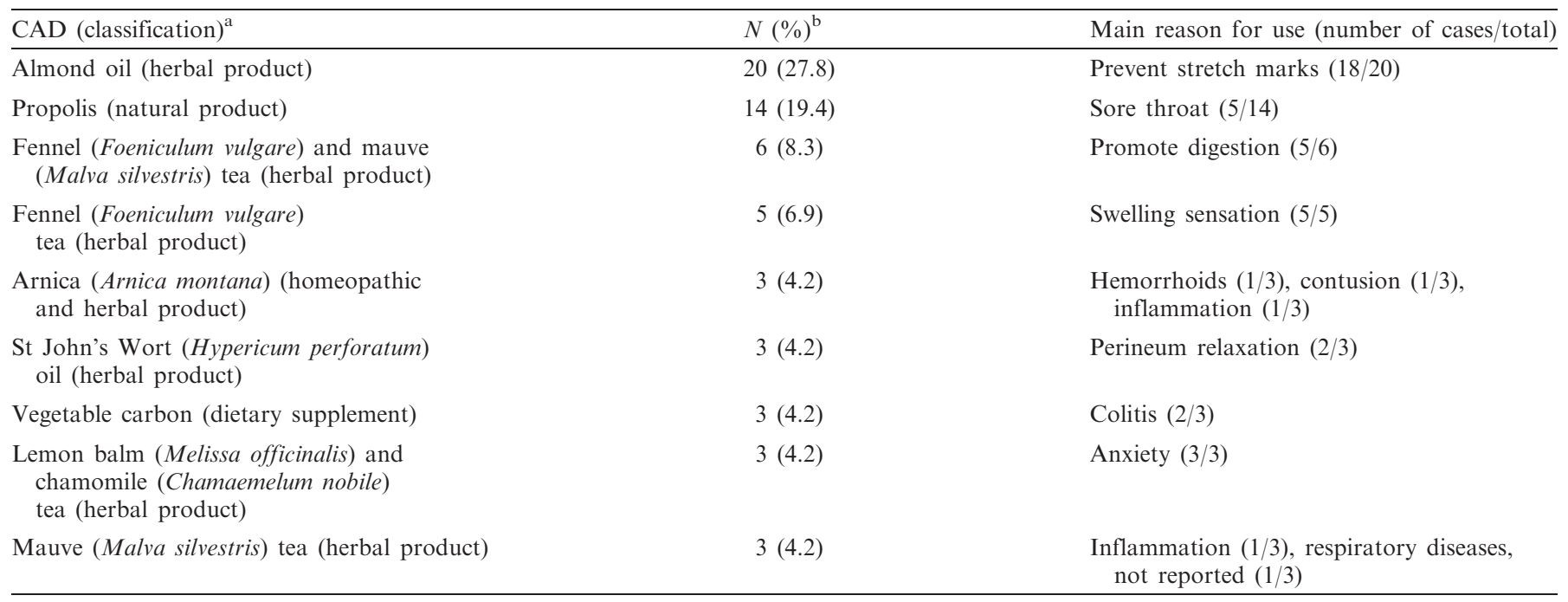

${ }^{\mathrm{a}}$ Classification based on European Pharmacopeia (18).

${ }^{\mathrm{b}}$ Only the products with a prevalence of use for three women or more were included in the Table. Denominator is the number of users $(n=72)$. 
Table 4. Analysis of variance (ANOVA) among mean number ( \pm SEM) of CADs by trimester patterns of use

\begin{tabular}{llllllll}
\hline \multicolumn{7}{c}{ Trimester } & \\
\hline 1st & 2nd & 3rd & 1st and 3rd & 2nd and 3rd & 1st, 2nd and 3rd & $F$ & $P$ \\
\hline $2.0 \pm 0.4$ & $1.6 \pm 0.2$ & $1.9 \pm 0.3$ & $2.0 \pm 0.0$ & $2.1 \pm 0.4$ & $2.6 \pm 0.9$ & 0.516 & 0.763 (NS) \\
\hline
\end{tabular}

NS: not significant.

SEM: Standard Error of Mean.

Table 5. Percentage of CADs wrongly ${ }^{\mathrm{a}}$ classified by the participants

\begin{tabular}{lc}
\hline $\begin{array}{l}\text { Wrong CADs } \\
\text { classification (\%) }\end{array}$ & $N(\%)$ \\
\hline 0 & $10(15.2)$ \\
50 & $11(16.7)$ \\
66 & $2(3.0)$ \\
75 & $1(1.5)$ \\
80 & $1(1.5)$ \\
83 & $1(1.5)$ \\
88 & $1(1.5)$ \\
100 & $39(59.1)$ \\
Total $^{\mathrm{b}}$ & $66(100)$ \\
\hline
\end{tabular}

${ }^{\mathrm{a}}$ Comparison was performed by means of European Pharmacopoeia (18). ${ }^{\mathrm{b}} 6 / 72(8.3 \%)$ subjects were not able to remember the type of product used, its classification or both.

$59.1 \%$ was not able to classify any of the products that they were using (Table 5).

The mean numbers of CADs used during the three pregnancy trimesters are reported in Table 5. No significant differences in the correct classification of CADs used were present among users in different trimesters of pregnancy (Table 6).

\section{Information Sources}

As expected, the primary information source for the majority of women during pregnancy were their gynecologist (32.6\%) and midwife (19.5\%) (Fig. 1). In contrast, outside of pregnancy, they mainly relied upon herbalists for information (50.4\%) (Fig. 2).

\section{Women's Beliefs about CADs}

The beliefs of participants about the safety and efficacy of CADs are shown in Fig. 3 and 4. More than a half $(52 \%)$ of the sample were convinced that CADs are safer than conventional medications during pregnancy, while $62.7 \%$ considered CADs as having equal efficacy as conventional drugs.

\section{Discussion}

This is the first Italian study investigating attitudes, beliefs and knowledge of CADs in pregnant women, and is also the first work conducted with the aim at characterizing CAD users. Although preliminary, these results emphasize that the use of CADs during pregnancy is a widespread habit among Italian women, who demonstrate not to be able to classify the CADs in the proper category. In fact $48 \%$ of the surveyed subjects used at least one CAD during the current pregnancy and 59.1\% was not able to classify any of the products that they were using.

The reliability and validity of the retrieved data are high, as confirmed by the 'very good' level of agreement reached by the test-to-retest analysis, as well as by means of the lie-catchers comparison.

The prevalence of CAD use seems to be higher in Italy than what is reported in studies performed in the USA and in other European countries. Most research on drug use in pregnancy reports between 3.6 and $15.9 \%$ CAD use (including homeopathic and herbal drugs) (24,25). Tsui et al. (26) conducted a survey among pregnant Californians, in whom $13.3 \%$ reported using dietary supplements. A paper of Nordeng et al. (27) investigated the use of herbal drugs in 400 pregnant Norwegian women reporting up to $36 \%$ use of herbal remedies. The most recent and larger investigation reported that about 1 out of 1000 pregnant women (787 of 860215 recorded in the Swedish national birth register) had taken herbal medications. Although this prevalence may seem low, it should be noted that data were referred only to the first trimester of pregnancy (16).

Also previous epidemiological studies conducted in Italy mainly dealt only with the use of herbal remedies. Zaffani et al. (17) conducted a research on 1044 randomly selected Italian women: $47.0 \%$ of the sample reported using at least one herbal product, including utilization in pregnancy or to treat their children's disease. Herbal products were mainly taken in combination with conventional drugs or homeopathic remedies.

The prevalence of CAD use during pregnancy reported in the present study $(48.0 \%)$ is consistent with what is reported by Zaffani et al. (17). Nevertheless, in our sample, no significant difference was present in sociodemographic variables between CAD users and nonusers, whereas Zaffani et al. reported a higher use among highly educated women, aged 31-40 years and employed, confirming previous results of studies performed in Italy (6) as well as in other countries $(2,4)$. However, it is worth mentioning that these studies were focused on phytotherapy, while the present research was aimed at 
Table 6. Analysis of variance (ANOVA) among mean percentages ( \pm SEM) of correctly classified CADs, by trimester patterns of use

\begin{tabular}{llllllll}
\hline \multicolumn{9}{c}{ Trimester } & \\
\hline 1st & 2 nd & 3rd & 1st and 3rd & 2nd and 3rd & 1st, 2nd and 3rd & $F$ & $P$ \\
\hline $61.8 \pm 14.8$ & $74.3 \pm 10.6$ & $76.4 \pm 8.4$ & $66.6 \pm 16.6$ & $72.5 \pm 13.1$ & $79.8 \pm 8.8$ & 0.283 & 0.920 (NS) \\
\hline
\end{tabular}

NS: not significant.

SEM: Standard Error of Mean.

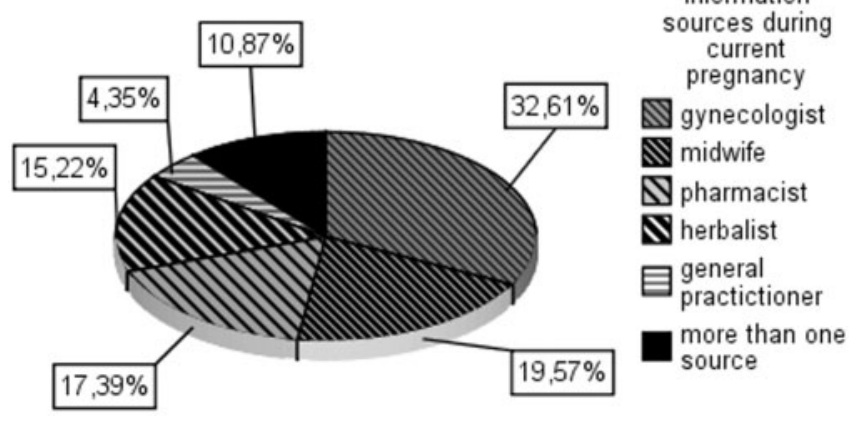

Figure 1. Information sources on CADs during current pregnancy $(n=150)$.

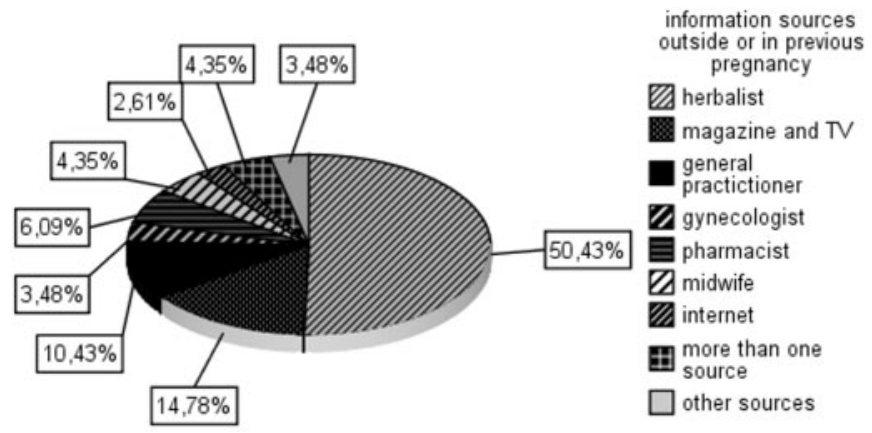

Figure 2. Information sources on CADs in previous pregnancy or outside of pregnancy $(n=150)$.

exploring the use of any so-called 'products manufactured from herbs and/or with a natural origin'. So these socio-demographic features may therefore pertain to subjects seeking a phytotherapeutic approach, while the use of CADs appears, in general, to be less restricted to social classes.

The two most important variables with predictor meaning were identified as (i) current use of conventional drugs and (ii) habitual use of CADs (other than in current pregnancy). The first one has been reported only in univariate analysis because one cell revealed a null value. The latter one is the most interesting factor: adjusted OR revealed a 10.8 -fold increase concerning the risk of CAD use in pregnancy if the woman was a habitual user of this kind of therapy.

The importance of identifying risk factors for CAD use in pregnancy underlies the possible maternal and foetal damage of some non-conventional medications. For instance, recent research $(28,29)$ showed the possible teratogenic effect of several Chinese herbal medicines

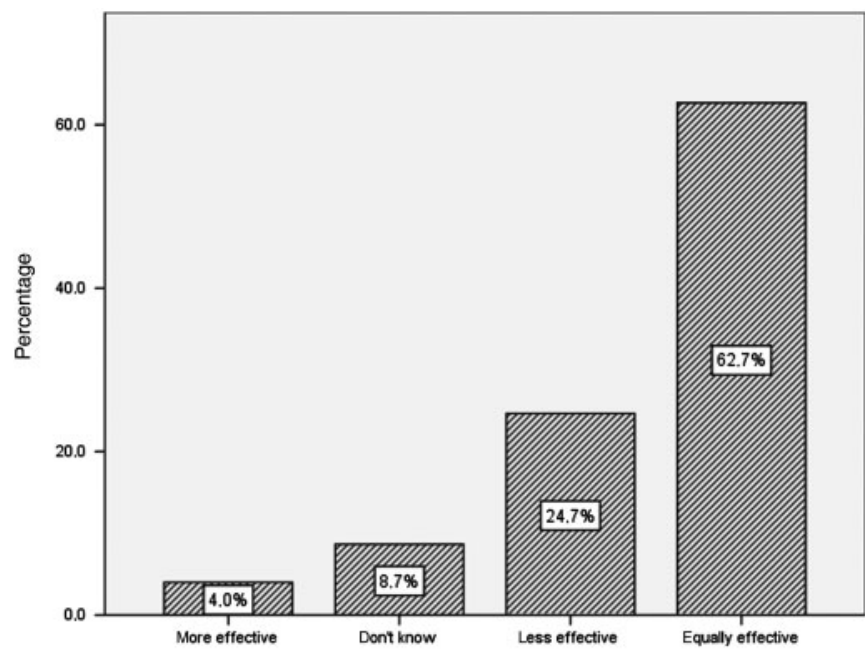

Figure 3. Pregnant women's opinions about efficacy of CADs when compared with traditional medications $(n=150)$.

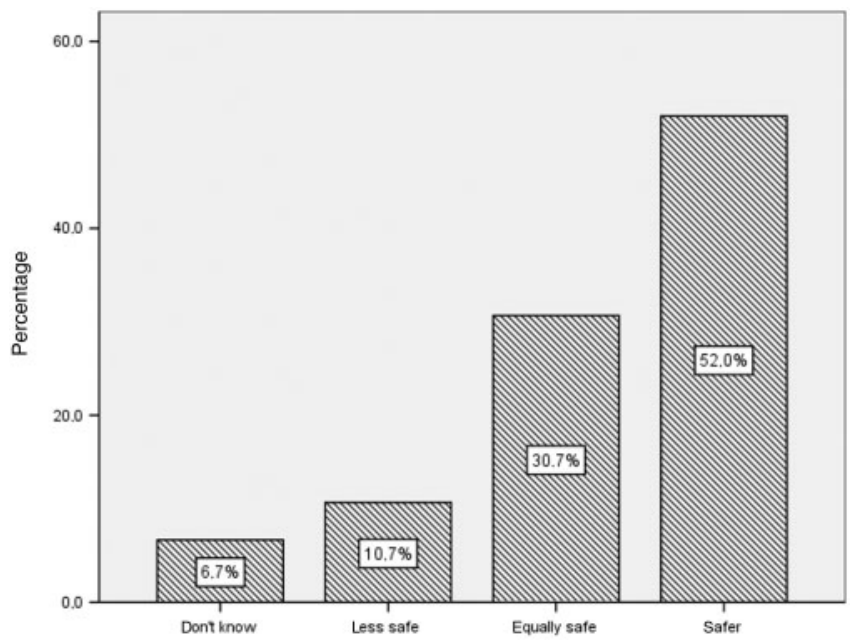

Figure 4. Pregnant women's opinions about safety of CADs when compared with traditional medications $(n=150)$.

when used during pregnancy. Holst and coworkers (16) reported no signs of unfavorable effect of herbal drug use on pregnancy outcome; nevertheless, they did not exclude possible rare adverse effects such as foetal malformations. For example, the safety profile of Ginseng, Valerian, St. John's Wort, Gingko, Propolis, Chamomile is not clearly defined and, for some of them, their use in pregnancy is contraindicated because of the potential harm for the mother and/or foetus as well as the potential adverse effect affecting childbirth (8-14). 
In this context it is worth mentioning the recent paper of Tournaire et al. (30) discussing the role of complementary and alternative therapies in reducing pain during delivery. Many CAM remedies could be used in this context, but healthcare providers are still unready to apply a correct evidence-based approach because of their poor knowledge and the scanty data availability. Also for these reasons, the possibility of identifying CADs users before attempting a pregnancy, might be very useful also for the application of non-conventional therapies to facilitate the delivery.

Additionally, a feature that was not previously assessed in other research is the knowledge that women have about the nature of assumed CADs. A high level of wrong classification of CADs could expose women and/ or the foetus to additional risks. Since the CAM area includes different heterogeneous aspects and disciplines, it is not surprising that users may be mislead when asked to classify CADs. The clinical consequences of this problem could result in an evident risk of using, for example, an herbal drug or a natural product with the conviction of taking a homeopathic drug. In the present study, propolis, the second most used product in this survey, was always wrongly considered a homeopathic remedy. This is quite relevant because, although its efficacy still remains controversial (28), the safety of propolis is widely questioned. This natural product is not devoid of adverse effects, some of which are extremely severe such as anaphylactic shock (31). Consistenly, St. John's Wort and chamomile, assumed by $4.2 \%$ of the participants, are not supported by an adequate information on their safety profile in pregnancy, and women could use these preparations without knowing their actual formulation (8-14). On this purpose a fatal case report of anaphylaxis due to chamomile tea during pregnancy has been reported (32).

The increased risk of taking CADs during the first and second trimester of pregnancy (higher teratogenic risk) was also unknown to most of the women in the study. The prevalence of CAD use was similar during the three trimesters and the percent of wrong classification of CADs was also the same. Consistently, pregnant women seem to be confident with CADs and more than half of them considered CADs safer than conventional medicines. A positive note emerging from these data is that pregnant women refer primarily to gynecologists and midwives as their principal source of information for CAD use during pregnancy. However, only $32.6 \%$ of participants consulted a healthcare professional from the obstetrics field, confirming the risk that CADs could be used without an accurate clinical control. This is quite similar to what happens outside pregnancy; in fact, more than $60 \%$ of subjects, using alternative treatments, do not report the use to their doctor (4).

Yet, out of pregnancy, participants seem commonly to consult an herbalist to receive advice on CADs. In other studies pregnant women referred to herbal stores and pharmacies or generally used herbal drugs on their own initiative $(33,17)$. This kind of behavior could have important clinical consequences, especially in Italy and in other countries where herbalists are not professional healthcare givers, and their suggestions in terms of efficacy and safety of CADs, both to pregnant and non-pregnant women, could be misleading.

\section{Limitations}

A limitation of this survey was reliance on a non-random sampling procedure for the questionnaire phase. This issue, together with the small sample enrolled, may affect the transferability of our findings to the whole population. Moreover the items that investigated the previous use of CADs could be affected by recall bias. Finally, the higher prevalence of well-educated women ( $72 \%$ reported a university degree) might have influenced the analysis in terms of the participants' capability of classifying CADs.

\section{Conclusions}

This preliminary study confirms the need of exploring the attitudes, beliefs and knowledge of CADs among Italian pregnant women. In light of the validity and reliability of the questionnaire, these results suggest the necessity of developing counselling strategies focusing on CAD use during pregnancy, especially for habitual users. Since in Italy, as in many other Western countries, standardized scientific testing of CADs is not required by regulatory agencies before marketing, their use in pregnancy should always be under the guidance of an expert physician. In this context, an effective information campaign concerning these products appears fundamental for pregnant Italian women, who seem to consider a product labeled 'natural' as being synonymous with 'safe'.

\section{Acknowledgements}

The authors would like to thank all midwives and gynecologists who took part in the study planning and data collection and to the women who entered the study.

\section{References}

1. National Center for Complementary and Alternative Medicine (NCCAM). Available at: http://nccam.nih.gov/.

2. Goldbeck-Wood S, Dally M. Complementary medicine is booming worldwide. BMJ 2007;313:131-3.

3. World Health Organization. Fact Sheet No 134: Traditional Medicine. 2003. Available at: http://www.who.int/mediacentre/factsheets/fs $134 / \mathrm{en} /$ index.html.

4. Eisenberg DM, Davis RB, Ettner SL, Appel S, Wilkey S, Van Rompay M, et al. Trends in alternative medicine use in the United States, 1990-1997: results of a follow-up national survey. JAMA 1998;280:1569-75. 
5. Forster DA, Denning A, Wills G, Bolger M, McCarthy E. Herbal medicine use during pregnancy in a group of Australian women. BMC Pregnancy Childbirth 2006;19:21.

6. Menniti-Ippolito F, Gargiulo L, Bologna E, Forcella E, Raschetti R. Use of unconventional medicine in Italy: a nationwide survey. Eur J Clin Pharmacol 2002;58:61-4.

7. Einarson A, Lawrimore T, Brand P, Gallo M, Rotatone C, Koren G. Attitudes and practices of physicians and naturopaths toward herbal products, including use during pregnancy and lactation. Can J Clin Pharmacol 2000;7:45-9.

8. Friedman JM. Teratology society: presentation to the FDA public meeting on safety issues associated with the use of dietary supplements during pregnancy. Teratology 2000;62:134-7.

9. Rousseaux CG, Schachter H. Regulatory issues concerning the safety, efficacy and quality of herbal remedies. Birth Defects Res B Dev Reprod Toxicol 2003;68:505-10.

10. Tiran D. The use of herbs by pregnant and childbearing women: a risk-benefit assessment. Complement Ther Nurs Midwifery 2003;9:176-81.

11. Tiran D. Complementary therapies in maternity care: personal reflections on the last decade. Complement Ther Clin Pract 2005; 11:48-50.

12. Tiran D. NICE guideline on antenatal care: routine care for the healthy pregnant woman-recommendations on the use of complementary therapies do not promote clinical excellence. Complement Ther Clin Pract 2005;11:127-9.

13. Tiran D. Complementary medicine in pregnancy and birth. Pract Midwife 2005;8:12-16.

14. Tiran D. Complementary therapies in pregnancy: midwives' and obstetricians' appreciation of risk. Complement Ther Clin Pract 2006;12:126-31.

15. Mabina MH, Pitsoe SB, Moodley J. The effect of traditional herbal medicines on pregnancy outcome. The King Edward VIII Hospital experience. S Afr Med J 1997;87:1008-10.

16. Holst L, Nordeng H, Haavik S. Use of herbal drugs during early pregnancy in relation to maternal characteristics and pregnancy outcome. Pharmacoepidemiol Drug Saf 2008;17:151-9.

17. Zaffani S, Cuzzolin L, Benoni G. Herbal products: behaviors and beliefs among Italian women. Pharmacoepidemiol Drug Saf 2006;15:354-9.

18. European Pharmacopoeia. Available at: http://www.omeomed.net/ sub_index/link.php\#Farmacopea.
19. Boynton PM. Administering, analysing, and reporting your questionnaire. BMJ 2004;328:1372-5.

20. Boynton PM, Greenhalgh T. Selecting, designing, and developing your questionnaire. BMJ 2004;328:1312-15.

21. Richardson J. Design and conduct a survey. Complement Ther Med 2005; 13:47-53

22. Groves RM, Fowler FJ, Couper MP. Survey Methodology. Wiley and Sons, 2007.

23. Rosen T, Olsen J. Invited commentary: the art of making questionnaires better. Am J Epidemiol 2006;164:11459.

24. Hemminki E, Mantyranta T, Malin M, Koponen P. A survey on the use of alternative drugs during pregnancy. Scand J Soc Med 1991;19:199-204.

25. Lacroix I, Damase-Michel C, Lapeyre-Mestre M, Montastruc JL. Prescription of drugs during pregnancy in France. Lancet 2000;356:1735-6.

26. Tsui B, Dennehy CE, Tsourounis C. A survey of dietary supplement use during pregnancy at an academic medical center. Am J Obstet Gynecol 2001;185:433-7.

27. Nordeng H, Havnen GC. Use of herbal drugs in pregnancy: a survey among 400 Norwegian women. Pharmacoepidemiol Drug Saf 2004;13:371-80.

28. Chuang CH, Hsieh WS, Guo YL, Tsai YJ, Chang PJ, Lin SJ, Chen PC. Chinese herbal medicines used in pregnancy: a population-based survey in Taiwan. Pharmacoepidemiol Drug Saf 2006;16:464-8.

29. Chuang CH, Doyle P, Wang JD, Chang PJ, Lai JN, Chen PC. Herbal medicines used during the first trimester and major congenital malformations: an analysis of data from a pregnancy cohort study. Drug Saf 2006;29:537-48.

30. Tournaire M, Theau-Yonneau A. Complementary and alternative approaches to pain relief during labor. Evid Based Complement Alternat Med 2007:4:409-17.

31. Hsu CY, Chiang WC, Weng TI, Chen WJ, Yuan A. Laryngeal edema and anaphalactic shock after topical propolis use for acute pharyngitis. Am J Emerg Med 2004;22:432-3.

32. Newall CA, Anderson LA, Phillipson JD. Herbal Medicines. A Guide for Health-Care Professionals. Cambridge: The Pharmaceutical Press, 1996.

33. Nordeng H, Havnen GC. Impact of socio-demographic factors, knowledge and attitude on the use of herbal drugs in pregnancy. Acta Obstet Gynecol Scand 2005;84:26-33.

Received December 6, 2007; accepted April 4, 2008 
Appendix 1

Face-to face questionnaire administred by a trained midwife after the explanation to pregnant women concerning definition of Complentary and Alternative Drugs (CADs).

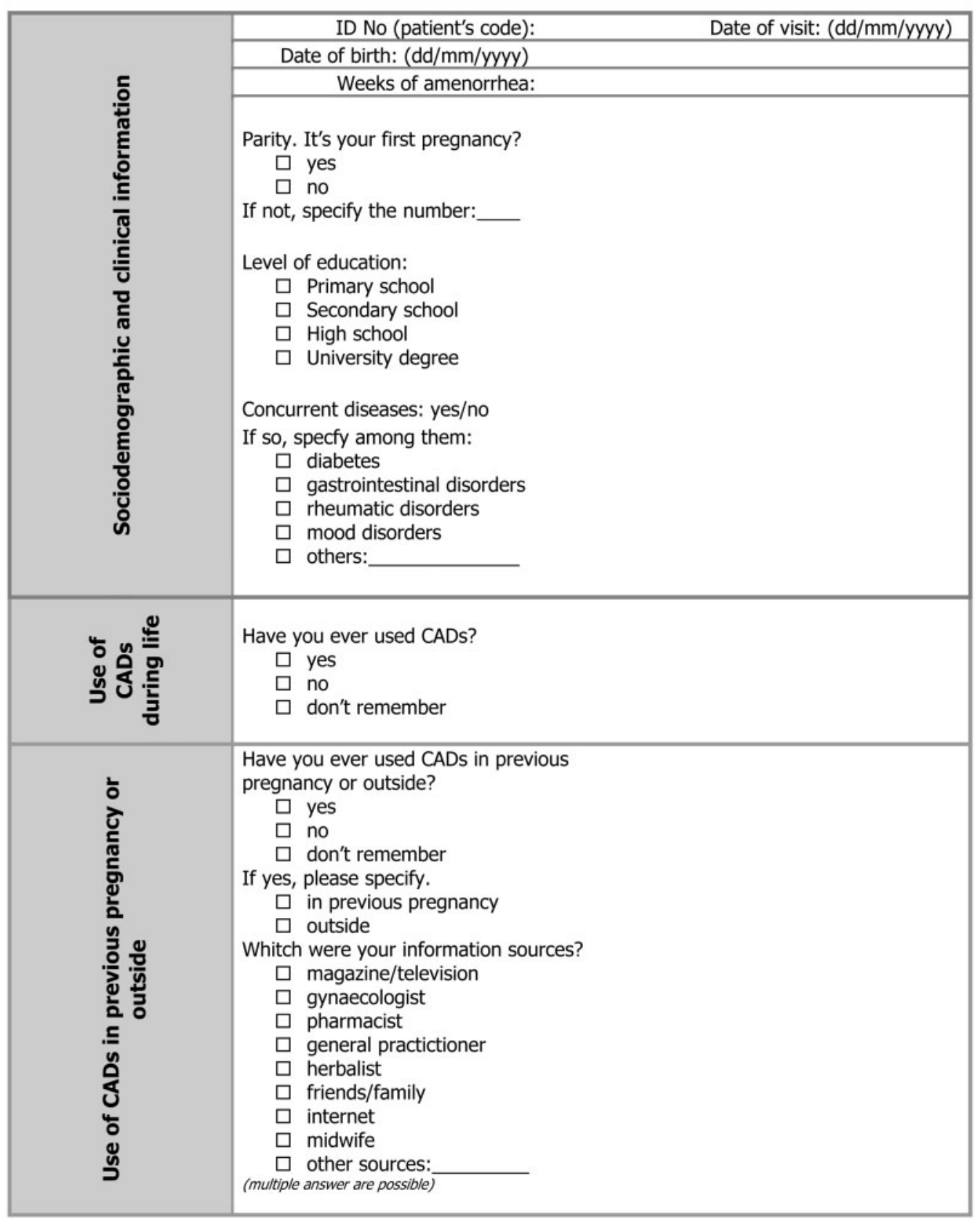




\begin{tabular}{|c|c|}
\hline 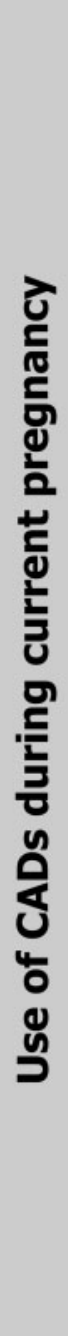 & 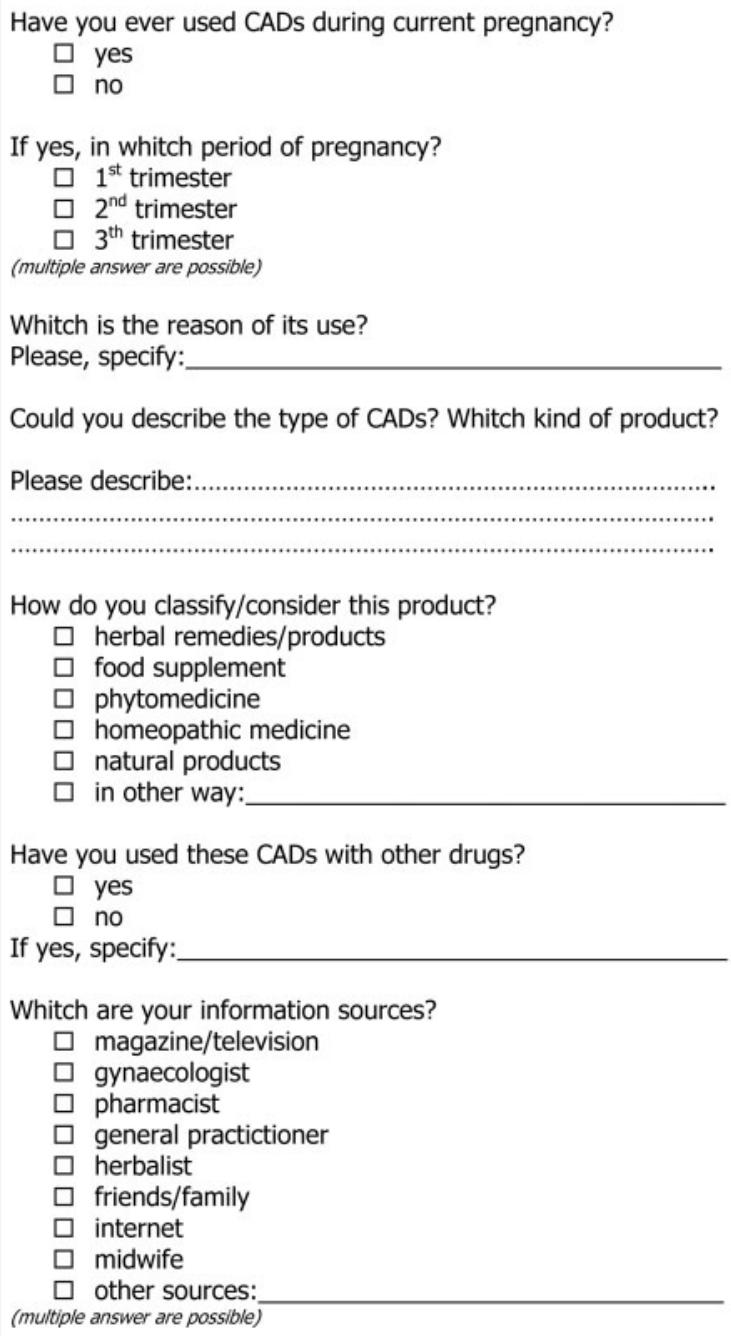 \\
\hline
\end{tabular}

\begin{tabular}{|c|c|}
\hline 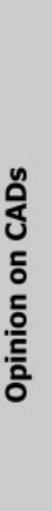 & 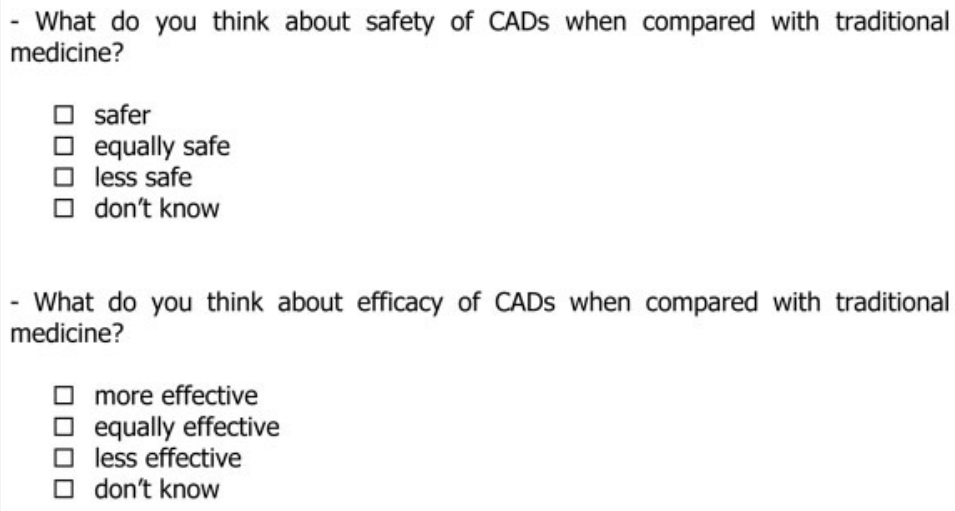 \\
\hline & Signature of attending midwife \\
\hline
\end{tabular}




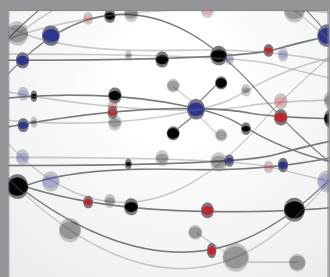

The Scientific World Journal
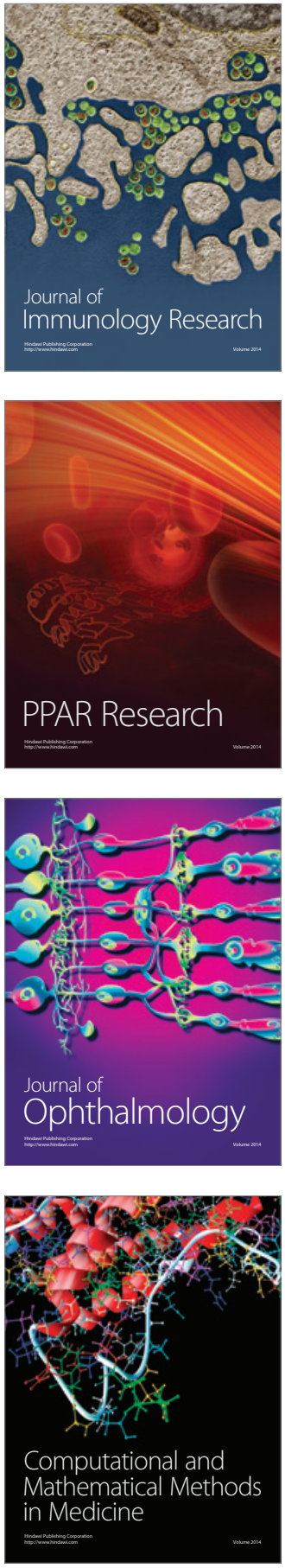

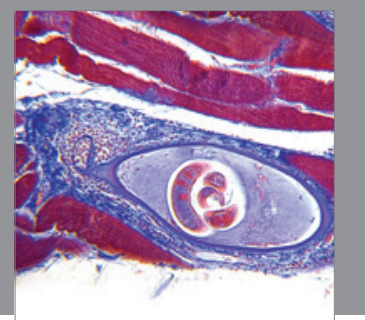

Gastroenterology

Research and Practice
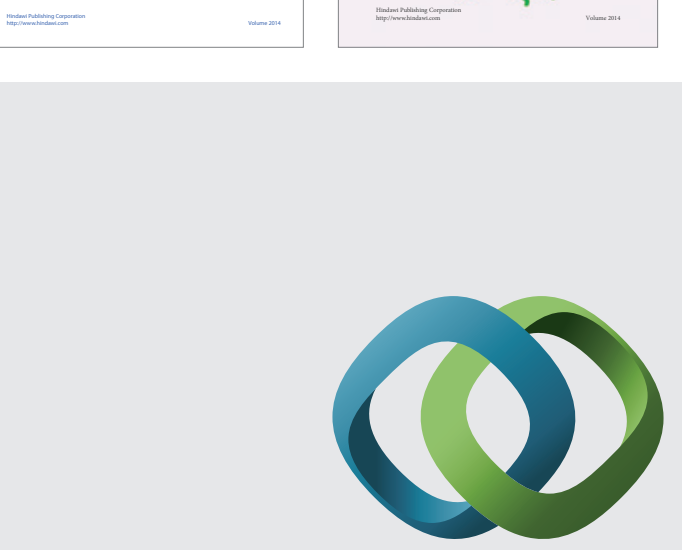

\section{Hindawi}

Submit your manuscripts at

http://www.hindawi.com
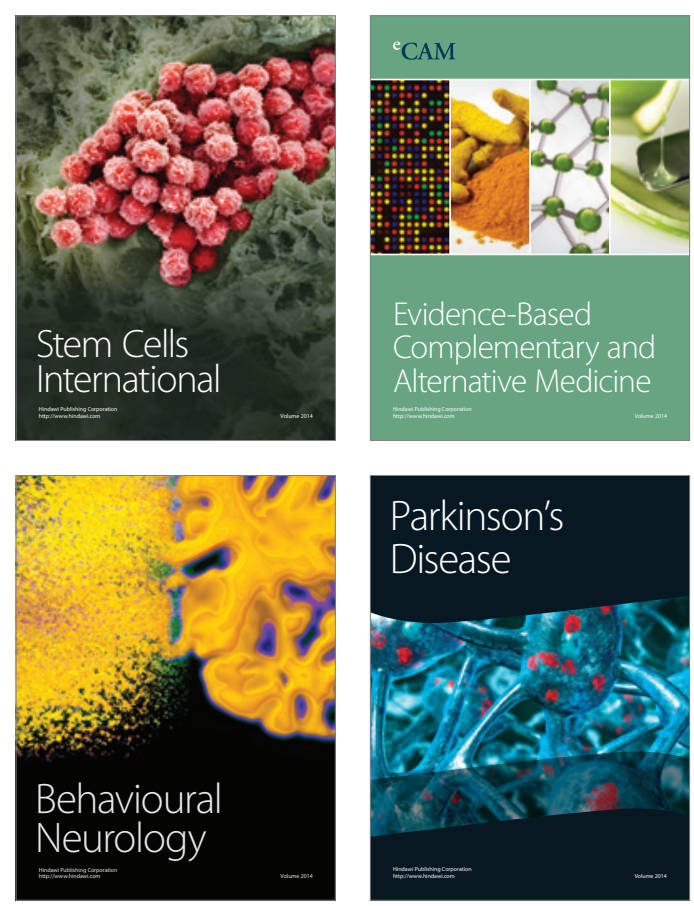

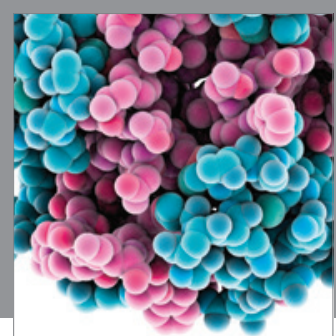

Journal of
Diabetes Research

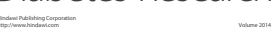

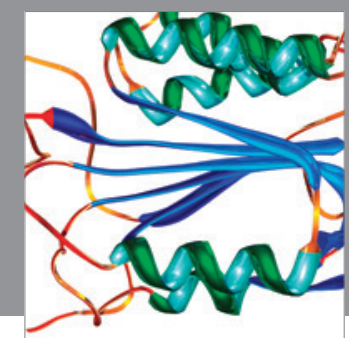

Disease Markers
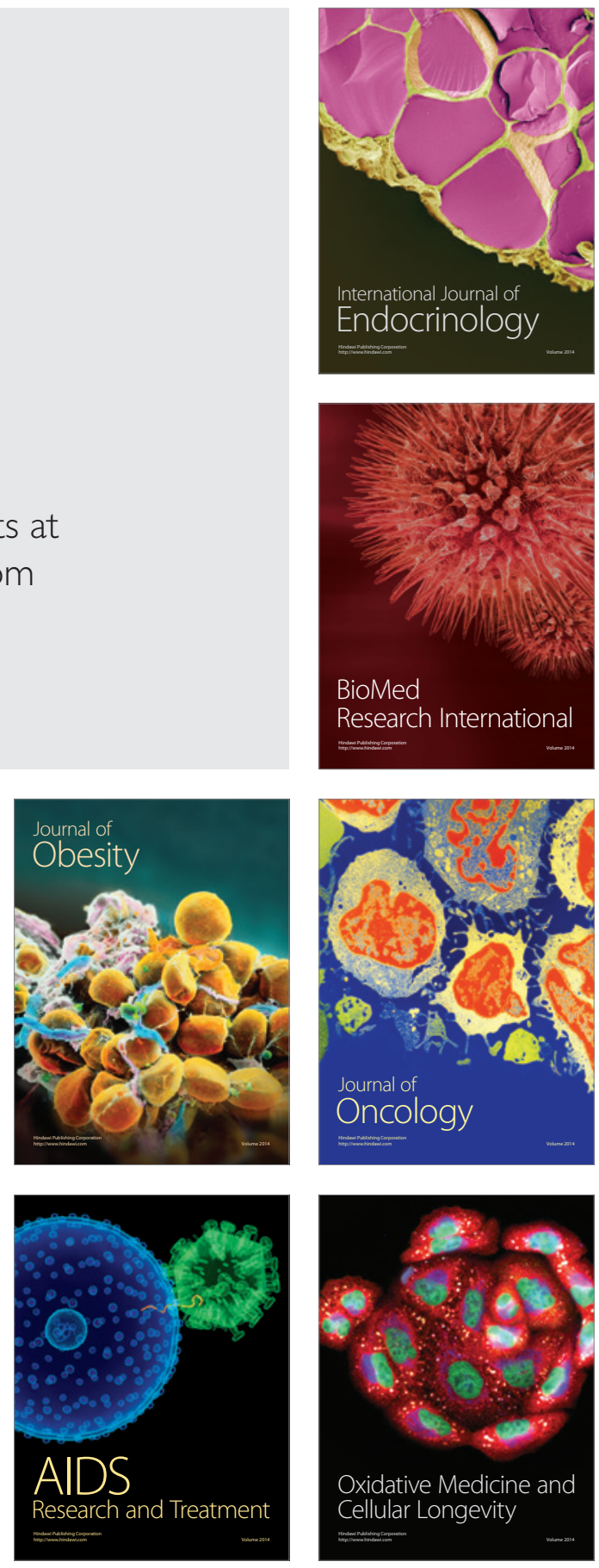